\title{
New Wine in Old Bottles: The Changing Socioeconomic Drivers of Sprawl during Building Boom and Stagnation
}

\author{
Luca Salvati $^{1}$, Adele Sateriano ${ }^{1}$, Efstathios Grigoriadis ${ }^{2}$, Margherita Carlucci $^{3}$ \\ ${ }^{1}$ Council for Agricultural Research and Economics (CREA), Via della Navicella 2-4, I- \\ 00184 Rome, Italy \\ ${ }^{2}$ Sapienza University of Rome, Department of Architecture and Project, Via Flaminia 359, \\ I-00196 Rome, Italy \\ ${ }^{3}$ Sapienza University of Rome, Department of Social and Economic Science, Piazzale A. \\ Moro 5, I-00185 Rome, Italy
}

Corresponding author:

Luca Salvati, $\mathrm{PhD}$

Tel: +3967005413

Fax: +39067005711

E-mail addresses: luca.salvati@uniroma1.it 


\title{
New Wine in Old Bottles: The Changing Socioeconomic Drivers of Sprawl during Building Boom and Stagnation
}

\begin{abstract}
European cities are shifting towards more scattered urban models while at the same time experiencing relevant changes in the local socioeconomic context. With the aim to identify possibly relevant associations with different urban patterns, this study compares the socioeconomic profile of districts with respectively continuous and discontinuous settlements along the urban gradient in Rome, Italy, during building boom (early-1970s) and stagnation (late-2000s). Non-parametric correlation statistics and multivariate techniques were used to assess the spatio-temporal evolution of 24 socioeconomic indicators (population, settlement, labor market, economic structure) and 14 landscape, territorial and topographic indicators at the local scale (urban districts and municipalities). The socioeconomic context characterizing discontinuous vs. continuous settlements in the early 1970s was significantly different from what was observed in the late 2000s. In the early 1970s, economic structure and labor market variables played a major role, while demographic variables and a mixed composition of the natural landscape surrounding discontinuous settlements were discriminant in the late 2000s. Policies oriented to urban sustainability and sprawl containment may benefit from an in-depth understanding of the different socioeconomic contexts associated with scattered settlements in expansion and recession times.
\end{abstract}

Key words: Demography, Economic structure, Labor market, Indicators, Mediterranean region. 


\section{Introduction}

In the last decades, dense/compact growth and population increase in urban centers have been progressively replaced by a discontinuous expansion reflecting population deconcentration in suburban rings progressively far from central cities (Catalàn et al., 2008; Arapoglou and Sayas, 2009; Terzi and Bolen, 2009; Garcia-Palomares, 2010). Discontinuous urbanization has been demonstrated to favor class segregation (Lemanski, 2007; Maloutas, 2007; Dujardin et al., 2008; Arapoglou and Sayas, 2009) and inner city gentrification (DuraGuimera, 2003; Hatz, 2009; Bayona-Carrasco and Gil-Alonso, 2012), as well as urban congestion and increases in energy demand (Galster et al., 2001; Kahn, 2000; Helbich, 2012), loss in local culture, traditions and practices (Beriatos and Gospodini, 2004; Nuissl and Rink, 2005; Andersson, 2006; Leontidou et al., 2007), landscape fragmentation (Irwin and Bockstael, 2004) and loss of natural resources (Alberti, 2005). On the other side, the impacts on urban local competitiveness are uncertain (Camagni et al., 2002; Pacione, 2005; Lang et al., 2009).

Compared with Anglo-American metropolitan regions (Gordon and Cox, 2012), continuous and compact urban expansion was the most common pattern of growth for cities in continental Europe (Alphan, 2003; Garcia and Riera, 2003; Tsai, 2005; Gospodini, 2009; Salvati et al., 2013), especially where long-established development paths and planning practices result in specific settlement characteristics and urban morphologies (Couch et al., 2007). However, after World War II, the rapid growth of European cities showed evidence of a transformation of compact mono-centric urban areas into more complex - scattered or polycentric - regional structures (Kasanko et al., 2006; Haase et al., 2010; Arribas-Bel et al., 2011; Kabisch and Haase, 2011). By prefiguring polycentric development as a tool to achieve more cohesive and spatially-balanced territories (Kloosterman and Musterd, 2001; Coccossis et al., 2005; Giannakourou, 2005; Rivolin and Faludi, 2005; Faludi, 2006), the European Spatial Planning Framework has driven, at least indirectly, urban transformations toward more dispersed morphologies and decentralized functions in the last two decades. As a consequence, mixed and indistinct urban continuums expanded into agricultural and semi-natural land modifying a socioeconomic structures traditionally oriented along the urban gradient (Richardson and Chang-Hee, 
2004; Schneider and Woodcock, 2008; Schwarz et al., 2010; Sarzynski et al., 2014). This process was partly driven even by the economic decline of rural areas around big cities (Phelps et al., 2006, Longhi and Musolesi, 2007; Turok and Mykhnenko, 2007). Demographic dynamics too consolidated the gap between urban regions and rural areas accentuating the decline of economically-disadvantaged and marginal districts (Cohen, 2006; Angel et al., 2011; Haase and Totzer, 2012).

With discontinuous and dispersed settlements expanding into rural areas (Muñoz, 2003; Paul and Tonts, 2005; Salvati and Sabbi, 2011; Chorianopoulos et al., 2014), the restructuring of European cities has also determined new - and more subtle - forms of economic polarization and social inequalities (Kourliouros, 1997; Balibrea, 2001; Dura Guimera 2003, Delladetsima, 2006; Maloutas 2007; Melįh Pinarcioğlu and Işik, 2009).

Taken as one of the most influential processes of urban transformation along the last century, suburbanization - influenced by a variety of contextual factors (Bourne, 1996; Bruegmann, 2005; European Environment Agency, 2006) - has been the object of a vast literature. Couch et al. (2007) reviewed suburbanization trends in Europe classifying cities according to demographic, social and economic attributes reflected into distinct models of sprawl. Sprawl 'patterns' and 'processes' have been increasingly investigated (Muñoz, 2003; Schwarz et al., 2010; Sarzynski et al., 2014, among others) pointing out the inherent diversity in the approaches proposed by social sciences. As the result of a complex actors' system, a multifaceted stratification of immediate and underlying causes was seen influencing (and in turn being influenced by) urban sprawl (Leontidou et al., 2007). However, the causes and consequences of urban sprawl were frequently debated without producing a general interpretative scheme (see, for instance, Salvati et al., 2013; Laidley, 2015; Oueslati et al., 2015).

As many other socio-economic processes, sprawl could be investigated according to a model-driven or a data-driven approach. In their seminal work on the causes of sprawl, Burchfield et al. (2006) tested the monocentric model and its generalization on U.S. metropolitan areas, also adding the impacts of physical (presence of aquifers in the urban fringe, temperate climate, rugged terrain) and political (local land use regulation, fiscal externalities of new developments) factors. However, to face the problem of endogeneity in economic predictors, some assumptions were needed, such as the concept of an average city 
to characterize which economic sectors have more centralized employment. Econometric techniques based on underlying economic theory and distributional assumptions might fail to capture the heterogeneity of urban processes and thus 'lack some generality in their findings' (Magliocca et al., 2015, p. 115) (

In this framework, an exploratory, data-driven approach could be of use, since, due to their inherent complexity, sprawl processes require comparative investigation to link urban expansion and the related population traits with spatially-varying social structures and economic performances changing over time (Chorianopoulos et al., 2010). Assessing the socioeconomic profile of local districts with different building density and morphology or, in other words, identifying profiles associated with sprawled settlements, allows to evaluate the contribution of external and internal variables (e.g. institutional, socioeconomic, cultural and political) to urban transformations. Local-scale investigation is especially needed to address urban sprawl as a multifaceted issue in different phases of post-war urbanization in Europe and especially in southern Europe (e.g. Salvati and Gargiulo Morelli, 2014).

In fact, the European Mediterranean cities showed peculiar trends of urbanization and suburbanization (Leontidou, 1990). The socioeconomic structure of several Mediterranean cities well reflect their location 'in-between the north-western 'global' cities and the developing agglomerations of the world south' (Leontidou, 1996). Other factors added to this complex picture (restricted public services and infrastructures, 'vertical' segregation coupled with a more traditional 'horizontal segregation', a 'popular land control' manifested through spontaneous building activities), with a distinct relationship between form and functions in respect to both northern and western counterparts (Allen et al., 2004; Kourliouros, 1997; Giaccaria and Minca, 2010; Salvati, 2014). Being frequently related to the increased preference for suburban areas reflected in the expansion of second homes (Leontidou et al., 2007), in Mediterranean cities, sprawl altered the traditional organization of urban and peri-urban spaces with multiple (private and public) actors competing for the use of non-urban land (Delladetsima, 2006).

Studies of the interactions between 'urban form' and 'economic functions' could help to understand the complexity of recent urbanization processes in the Mediterranean region (e.g. Evans, 2003; Couch et al., 2005; Allegretti and Cellamare, 2008; De Muro et al., 2011). 
The inherent complexity of Mediterranean cities and their urban dynamics (Salvati et al., 2013). assumed typical patterns and revealed unexpectedly complex relationships with processes involving historical, cultural and environmental factors in Rome, Italy. Rome is a region where different forms of sprawl manifested,possibly with distinct causes and underlying factors. Discontinuous settlements were firstly observed in the 1960s and 1970s as a response to weak urban planning and to policies boosting economic growth without any form of territorial coordination (Costa, 1991). A scattered expansion was observed in the following decades intermixed with urban re-polarization at the local scale (Salvati and Sabbi, 2011). The present study investigates different forms of sprawl, in the attempt to underpin the multiple factors underlying urban dispersion in two phases of Rome's growth - the building boom of the early 1970s and the economic stagnation observed in the late 2000s. We introduced an exploratory framework analyzing a comprehensive set of sociodemographic, economic and territorial indicators taken as candidate drivers of suburbanization. By pointing to different causes of sprawl in the two periods, this paper contributes to the long-lasting debate on European suburbanization highlighting the role of local actors and place-specific factors in a comparative perspective.

\section{Methodology}

\section{Study area}

The investigated area $\left(5,355 \mathrm{~km}^{2}\right)$ coincides with the administrative province of Rome, central Italy, whose boundaries encompass the Functional Urban Area (FUA) defined by the Urban Audit/Urban Atlas programs (European Environment Agency, 2006). The area surrounding Rome is mainly devoted to agriculture (horticulture, cereals, tree crop, especially olive groves and vineyards, and pastures) and includes a small part of the Apennine mountain region distant more than $40 \mathrm{~km}$ from the inner city. The most important functions, mainly of national relevance and typical of a State Capital (Salvati and Sabbi, 2011), are concentrated in the Rome municipality. Traditionally, the city provides services related to the public sector and thrives on tourism thanks to its invaluable cultural heritage (Salvati, 2014). 
Rome province is administered by 122 municipalities. Because of its exceptional size $(1,285$ $\mathrm{km}^{2}$ ), Rome's municipality was divided into 114 urban districts for the purposes of this study, obtaining 235 elementary spatial domains (Figure 1). In this study, municipalities and urban districts were chosen as the elementary spatial unit since they allow for a detailed analysis of urbanization patterns linking land-use and the spatial distribution of socioeconomic indicators at different points in time. Municipalities have been often selected as the elementary spatial unit for both socioeconomic and land-use change analysis (see Salvati et al., 2013 and reference therein). Using this geographical domain allows a reliable match with statistical data collected in the framework of economic and socio-demographic official surveys, including population and building censuses. Municipalities are also considered a relevant spatial unit for urban planning since they act as the local authority in charge of land taxation, building permits and land-use destination in Italy (Salvati and Sabbi, 2011).

Since World War II Rome growth was fuelled by intense migration from southern Italy (Krumholtz, 1992). Although a municipal master plan was developed in 1962, informal settlements were developed throughout the urban area (Costa, 1991). In line with other European cities, discontinuous expansion stimulated by real estate speculation and deconcentration of the inner city were observed in the last decades in Rome, determining drastic changes in the use of land and reducing drastically the gap in population density between urban and rural areas (Salvati, 2014). According to the National Census of Households, $45.3 \%$ of nearly 300 thousand buildings in the area were developed before $1970,20.5 \%$ during $1971-1980$ and only $3.9 \%$ in $2006-2010$.

\section{Land-use maps}

Data used in this study were obtained from the elaboration of two (compatible) digital maps: (i) the CORINE-like 'agricultural and forest map of Rome prefecture' scaled 1: 50,000 and dated 1974 (CLC74), and (ii) the COOrdination of INformation on the Environment (CORINE) map scaled 1: 100,000 and dated 2006 (CLC06). These maps have been widely used in previous studies dealing with land-use changes in central Italy (see, for instance, Salvati and Sabbi, 2011). Since the hierarchical classification used in the two maps is 
comparable, land-use categories were reclassified into twelve classes: (i) arable land, (ii) heterogeneous agricultural areas, (iii) vineyards, (iv) olive groves, (v) orchards, (vi) forests, (vii) pastures, (viii) low vegetated areas and bare ground, (ix) continuous urban fabric, (x) discontinuous urban fabric, (xi) urban green areas and (xii) water bodies. Water bodies were excluded from further analysis due to the restricted class area. Urban areas include continuous urban fabric, discontinuous urban fabric and urban green areas. Statistical analysis was run at the polygon scale corresponding to the 235 spatial domains illustrated above. The area of each land-use class was calculated for every administrative spatial unit (municipalities and urban districts) on the basis of the 'intersect' tool provided with the ArcGIS software (ESRI inc., Redwoods, USA).

Sprawl and ontextual indicators

Urban economic literature provides many definitions for sprawl, each one highlighting some relevant issue or dimension. In this work, we move from the one in Altshuler and Gomez-lbanez (1993, p. 67) as "continuous low density residential development on the metropolitan fringe, ribbon low density development along major suburban highways, and development that leapfrogs past undeveloped land to leave a patchwork of developed and undeveloped tracts'. Hence, to arrive to an operational definition of sprawl we used the idea (Jaeger et al., 2010) of urban sprawl as a phenomenon that could be visually perceived in the landscape, and identified it with the incidence in each spatial unit of discontinuous urban fabric, i.e. sealed land with vegetation and bare soil occupying a discontinuous but relatively large area.

Thus, th class area occupied by discontinuous urban fabric was considered the dependent variable in this study. This land-use class corresponds to the '112' code of the CLC hierarchical nomenclature. Following Salvati and Carlucci (2015a), the degree of discontinuous settlements for each elementary spatial unit was calculated as the percent land surface covered by 'discontinuous urban fabric' in the total urban area. To compute descriptive statistics each spatial unit was classified in one of two groups based on a class threshold (percent area of 'discontinuous urban fabric' below or above 30\%). To assess the spatially-varying local contexts in the study area, 24 socio-demographic, economic and environmental indicators (Table 1) were selected and constructed according to Salvati 
(2014) with the aim to illustrate the latent relationship between the productive structure, socio-demographic attributes and territorial/topographic characteristics of each local context. Data were derived from the Census of Population and Buildings carried out in 1971 and 2001 by the Italian National Statistical Institute (Istat), as these census waves were compatible with the spatial division adopted in this study (and especially with the 'urban district' spatial partition). Indicators were grouped in four research dimensions: demography (8), urban settlements (5), labor market (6) and productive structure (5). Analysis was supplemented with 14 indicators for landscape (8) and topographic/territorial attributes (6). Spatially-disaggregated value added or (declared) personal income data are rather scarce in Italy especially for the early period of study (mid-1970s), thus we provided a map of 2006 declared personal income in Rome (using the same spatial division adopted for the remaining variables) to be used in exploratory analysis. Supplementary indicators include elevation, proximity to the sea coast, percentage of built-up areas, a dummy variable characterizing urban districts belonging to Rome's municipality as well as the distance from the inner city and the surface area of each spatial unit. The distance of each spatial unit from the inner city, geographically identified in Piazza Barberini (see Salvati et al., 2013 for the rationale behind), in Rome () was determined using the linear distance between polygon centroids calculated by way of the ArcGIS 'Zonal Geometry' tool. Although intended here as a control variable, the surface area administered by each municipality can be also regarded as a proxy for land availability to building (Salvati and Carlucci, 2015b).

\section{Data analysis}

Descriptive statistics were run to assess the spatial distribution of morphological and socioeconomic indicators at the geographical scale defined above. To produce an overview of sprawl patterns in different socioeconomic contexts, an exploratory data analysis was carried out including Spearman non-parametric correlation analysis, Principal Component Analysis and Regression Trees. Non-parametric Spearman rank tests were carried out to identify significant correlations between the percentage of discontinuous urban fabric and 
the contextual indicators. Significance was tested at $p<0.05$ after Bonferroni's correction for multiple comparisons.

A Principal Component Analysis (PCA) was performed on the data matrix composed by 38 active variables (the contextual indicators described above) measured at each of the 235 spatial units. The percentage of discontinuous urban fabric was considered as a supplementary variable in the PCA. The PCA was based on the correlation matrix selecting relevant components with eigenvalue $>3$. Two statistical tests were used to assess the quality of PCA outputs: the Keiser-Meyer-Olkin measure of sampling adequacy and Bartlett's test of sphericity (Salvati, 2014). The position of indicators and spatial units on the factorial plane was illustrated through the analysis of component loadings and scores.

A final analysis based on Decision Tree Learning (DTL) was developed to explore the multiple relationship between the spatial distribution of discontinuous urban expansion and the 38 contextual indicators in Rome. DTL is a technique commonly used in data mining when the predicted outcome is a real number (Rokach and Maimon, 2008). The final output of DTL techniques is a flow-chart-like structure called decision tree, where each non-leaf node denotes a test on a given attribute, each branch represents the outcome of a test, and each leaf node has a class label. The most common algorithms for constructing decision trees work iteratively by choosing a variable at each step that best splits the set of items (in this case, the 235 elementary spatial units) and use metrics to measure the homogeneity of the target variables within the subsets. We adopted a Classification And Regression Tree (CART) decision-tree algorithm incorporating the variance reduction metric.

\section{Results}

Urban expansion and the socioeconomic context

Discontinuous settlements expanded rapidly into non-urban-land during the investigated time period in Rome (Figure 1). In the early 1970s discontinuous settlements concentrated in northern and southern districts around the Rome Ring Road and along the Tyrrhenian coast, at an average distance of $11.5 \mathrm{~km}$ from the inner city. Afterwards, urbanization in 
Rome occurred not only on fringe or coastal areas but also around subcenters far away from the inner city. At the end of the observed period, the highest share of discontinuous settlements to the total urban area was observed in rural municipalities (Figure 2) at an average distance of $21.9 \mathrm{~km}$ from the inner city. A comparison with the income map for the same period (Figure 3) signs out a distinctive feature of the geography of wealthy in this area: affluent households do not leap. The chance of getting a glimpse of some pieces of the outstanding monumental heritage of Rome seems to count more than land availability. Thus, wealthy dwellings saturate the historical center and the neighborhoods built for the ruling classes of the various successive governments after the unification of Italy, at first close to the Aurelian walls and then gradually further away, finally moving along the Consular Roads where Roman Emperors had built their villas and their tombs. Hence, the map of income almost seems a photographic negative of the incidence of discontinuous settlements (lower panel, figure 1), in which light areas appear dark and vice versa.. Results of a non-parametric Spearman analysis identified significant pair-wise correlations between the dependent variable (the share of discontinuous settlements in the total urban area) and the 38 predictors (Figure 2).

The proportion of discontinuous settlements decreased with population aging in both the 1970s and 2000s, suggesting that younger families with more than 3 components settled preferentially in these areas irrespective of the socioeconomic context and the distance from the inner city. Moreover, discontinuous urban expansion is more frequent in local contexts with high availability of building land. Apart from these variables, a different correlation profile was observed for the early 1970s and the late 2000s as a result of important transformations in the urban landscape. In the early 1970s large houses were developed in discontinuous settlements as a result of second-home expansion along the sea coast, especially in districts with high availability of building land. Consequently, the early 1970s sprawl in Rome could be seen as the result of lassez-faire policies tolerating informal, dispersed settlements as a consequence of real estate speculation.

In late 2000s, discontinuous settlements expanded in areas with low population density, high unemployment rate and a relatively low participation to the job market. High percentages of workers in agriculture and industry (manufacture and constructions) and low percentages of entrepreneurs and workers in the financial sector were frequently 
observed in municipalities with discontinuous settlements. Dispersed settlements were developed at larger distances from Rome and are surrounded by a mixed landscape dominated by woodland, olive groves and heterogeneous agricultural areas. These results suggest that the late 2000s sprawl impacted especially rural contexts with moderate accessibility from Rome and, as income data suggested, was plumped by the demand of affordable housing by young families with scarce means.

\section{Exploring sprawl latent factors}

The PCA extracted three relevant axes explaining together $48 \%$ (early 1970s) and 52\% (late 2000s) of the total variance (Table 2 ). Positive loadings to component 1 ( $25 \%$ for the early 1970s) were observed for the distance from the inner city, elevation, share of woodland in the total landscape, population structural dependency, percentages of non-occupied houses and of workers in the primary sector. Negative loadings to component 1 were observed for population density, density of non-occupied houses, percentages of entrepreneurs on total workers, workers in commerce and finance sectors. Component $2(16 \%)$ was associated positively with indicators of population aging and negatively with the percentage of arable land, the average number of components per family and the rate of participation to the job market. Component $3(7 \%)$ was associated positively with the share of workers (industry and transport) in the total workforce and negatively with the average number of rooms per house. Taken together, component 1 represents a typical urban-rural gradient based on population density and distance from the central city. Component 2 illustrates a demographic gradient discriminating spatial units with young population from those with elder population. The share of discontinuous settlements in the total urban area was negatively correlated with component 2 . Component 3 identifies a more subtle gradient distinguishing residential settlements (mainly compact and dense) from industrial and service settlements located around the inner city. The three principal components extracted for the late 2000s revealed a similar loading structure. Component 2 illustrates the spatial distribution of discontinuous settlements as a variable associated to young population, percentage of families with $>3$ components and larger houses. 
Results of the regression tree run separately on the early 1970s and late 2000s data with the share of discontinuous settlements in the total urban area as the dependent variable are illustrated in Table 4. Taken together, the 235 elementary spatial units were classified into 29 partitions based on 23 threshold predictors (early 1970s) and into 22 partitions based on 17 threshold predictors (late 2000s). The relative importance of predictors in each regression tree was shown in Figure 3. The importance of regression predictors discriminating discontinuous settlements from other settlement types changed significantly between the 1970s and the 2000s. The most relevant predictors for the early-1970s (importance rate $>0.5$ ) include indicators of population structure, density and size of nonoccupied houses, labor market (participation and employment rates, percentage of entrepreneurs, percentage of workers in financial services), landscape composition (agricultural use of land including vineyards, arable land and heterogeneous cropland) and territorial variables (elevation, proximity to the sea, distance from the central city). The most relevant predictors in the late 2000s were the number of components per family, the density of unoccupied houses, indicators of population aging and the distance from the central city. Important predictors also include the percentage of workers in industry, transport and financial services, the share of employees in the total workforce, unemployment rate and population density. The most relevant landscape predictors were forests and arable land. These findings outline a specific socioeconomic profile for discontinuous settlements based on a dynamic demographic structure and unique economic and landscape attributes depending on the expansion phase (building boom or stagnation).

\section{Discussion}

Shedding light on the relationship between urban morphology and socioeconomic functions is a relevant contribution to monitoring and planning for a more sustainable and socially-cohesive urban development (Andersson, 2006). Sprawl evolved thanks to a dynamic interplay between population growth, economic expansion, changes in life-styles 
and the development of new information technologies, with market forces shaping dispersed urban expansion as the ultimate possibility for cities to thrive (Gordon and Cox, 2012). According to Salvati and Carlucci (2015a), "increased reliance on private car transportation, growing costs or reduced coverage of public utilities, higher energy demand, socioeconomic divisions, income disparities, racial segregation of neighbourhoods, job and housing mismatch are only some of the factors discriminating recent sprawl processes from traditional urbanization phenomena involving Europe since World War II, evidencing also some contrasting orientations towards urbanism between northern and southern Europe". Multi-dimensional exploratory approaches are especially required to identify spatially- and temporally-variable drivers of suburbanization in Europe. The use of high-resolution spatial partitions of interest for urban planning contributes to a better understanding of socioeconomic processes underlying dispersed urban expansion (Arribas-Bel et al., 2011).

Focusing on the spatio-temporal dynamics of multi-domain indicators along the urban gradient (Kroll and Kabisch, 2012), our study provides a comprehensive assessment of the socioeconomic profile of dispersed settlements in two representative phases of the expansion of a Mediterranean city (building boom and stagnation). While choosing Rome as an emblematic region to test for the existence of distinct sprawl models along the last thirty years of urban history, the results of this study can be extended to other contexts in Mediterranean Europe. Although sprawl is a relatively novel phenomenon contrasting typically-compact urban patterns, this study indicates how dispersed urbanization in southern Europe expanded into rural areas with impacts on the socioeconomic context at the local scale and the organization of entire urban regions (European Environment Agency, 2006).

Our results suggest that the early 1970s and late 2000s suburbanization waves influenced in a different way the socio-spatial structure in Rome (Salvati, 2014). Population settling in discontinuous residential areas had unique attributes in respect to the neighboring communities (De Muro et al., 2011). In Rome, gated communities were occasionally observed in dispersed settlements - compared to other Mediterranean cities, such as Barcelona or Athens (Dura Guimera, 2003; Muñoz, 2003; Leontidou et al., 2007; Maloutas, 2007). These evidences also differ from what was observed in western and northern 
Europe, where sprawl processes were associated primarily with gentrification of inner cities, polycentric urban expansion or infrastructural development (Richardson and ChangHee, 2004; Bruegmann, 2005; Couch et al., 2007).

Sprawl contrasts with the pro-urban ideology typically observed in southern Europe since very early times, which identifies central cities with progress and civilization opposed to rural areas mostly affected by economic backwardness, poverty, job shortage and poor accessibility (Leontidou, 1990). Instead of contributing to economic re-balancing and social homogenization, recent sprawl phenomena involving rural areas - in Rome and in other Mediterranean cities - have consolidated regional divides reproducing a sort of 'gated landscape' (Chorianopoulos et al., 2010). The different local context found in the two phases of suburbanization in Rome reflects the pervasiveness of planning deregulation and the divergent socioeconomic characteristics of discontinuous settlements compared with other settlement types (Salvati et al., 2013), outlining the intimate connection between territorial, socio-demographic and economic forces in suburban spaces.

A young population structure was the only aspect characterizing discontinuous settlements during both building boom and economic stagnation. Despite the general aging of population in Rome (Salvati, 2014), young (bourgeoisie) families with children were (and are) key actors demanding for suburban locations with specific housing characteristics (detached buildings with private gardens and swimming pools, close to fast roads connecting with the inner city). 'Family sprawl' was occasionally observed in other parts of Italy, especially in northern Italy or in the wealthiest districts of central Italy. At the same time, elder population does not seem a relevant actor of discontinuous urban expansion in Rome - either in the 1970s or in the 2000s - contrary to what was observed in the most accessible areas of northern Italy and in other Mediterranean and western Europe contexts (Salvati and Carlucci, 2015a).

Apart from the demographic structure, other indicators considered in the present study diverged in the two time intervals. The early 1970s 'sprawl model' in Rome resembled the post-war urban dynamics observed in other northern Mediterranean cities (urbanitzaciones in Spain, aftereta in Greece, among others) with sparse, informal housing expanded into fringe land due to the increased house demand (Beriatos and Gospodini, 2004; Gospodini, 2009; Chorianopoulos et al., 2014). Second-home expansion was observed along the sea 
coast being boosted by economic development and the diffusion of private mobility (Leontidou et al., 2007). Although land price was a variable influencing settlement patterns (Allen et al., 2004), the early 1970s sprawl reflected the (partial) failure of urban planning (Costa, 1991). As a consequence of planning deregulation, dispersed settlements grew along fringe land (Krumholtz, 1992) coexisting with intensive agriculture (arable land, vineyards, orchards). This created complex landscapes reflecting a sort of 'land-use mixité' already observed by Leontidou (1990) in Athens.

Thirty years later globalization, the increased role of finance, real estate speculation and a city path oriented towards 'immaterial growth' were at the base of a new form of discontinuous urbanization expanding into marginal, hilly and mountainous land (Dahlman, 2006; Delladetsima, 2006; Arapoglou and Sayas, 2009; Garcia-Palomares, 2010). A network of coordinated (private) actors promoted scattered real-estate development projects - frequently incorporated in more ambitious programs of local development (Salvati, 2014). Low-density discontinuous expansion in remote places with natural amenities was sometimes stimulated by local master plans offering cheap rural land for building (Turner, 2005). This new 'sprawl-goes-rural' model was alimented by the increased demand for second-homes by specific population segments such as middle-class young families (e.g. Lopez and Hynes, 2003; Laidley, 2015; Oueslati et al., 2015). This model reflects a particularly fragile socioeconomic context and contributes to landscape fragmentation.

Contrasting the early-1970s informal model, the late-2000s sprawl reflects a progressive saturation of Rome's fringe following the re-polarization and densification of suburban areas observed during the 1990s (Salvati and Carlucci, 2015b). Rural sprawl had social impacts - possibly more relevant than those observed for the informal expansion of the 1970s. Sprawl determined the increase of 'gated communities' in rural areas experiencing cropland abandonment, poverty and job shortage. How migration, segregation and filtering processes - in the light of drastic changes in lifestyle and behaviors - may influence this sprawl model is an interesting issue which deserves further investigation. Moreover, the role of place-specific public regulations (e.g. land-use planning, housing policies, taxes, subsidies) is central to this framework and needs to be clarified in a comparative perspective (Anthony, 2004). 
Regional planning identifying the multiple drivers of sprawl represents an important challenge for policies oriented towards urban sustainability. To be more effective, policies aimed at containing sprawl should consider the variability of the local context as reflected in the various phases of urban expansion (Salvati et al., 2013). Indeed, the increased complexity in the relationship between morphology and socioeconomic functions may prevent designing effective strategies of urban containment at national or supra-national scale. By contrast, place-specific urban policies can better address the latent nexus between socio-demographic factors and suburbanization patterns and the role of spatial heterogeneity in local contexts undergoing dispersed urban expansion. Understanding how spatial heterogeneity - together with e.g. class segregation, informal economy and landscape fragmentation - shapes the distribution of discontinuous settlements in Mediterranean cities is a relevant issue deserving further investigation.

\section{Conclusions}

The present study emphasizes the role of demographic and economic factors at the base of sprawl models showing different levels of social cohesion, economic competitiveness and environmental awareness. These models are the result of non-linear urban cycles based on subsequent waves of compact and dispersed growth and fuelled by rapidly-evolving socioeconomic drivers. The unpredictable behaviors of the representative territorial actors focused on decision variables in turn influenced by broader forces - added to an already complex reading frame typical of the Mediterranean city. Although recent planning strategies in Rome were oriented towards the reduction of the socioeconomic gap between the central city and the surrounding region, discontinuous settlements expanding towards rural districts may act in the reverse way, contributing to strengthen the divide between urban and rural areas. This may vanish the efforts towards a more polycentric and spatially balanced growth promoted by Rome strategic Master Plan (Salvati, 2014). Policies targeting social cohesion, urban competitiveness and sustainable development are required to cope with suburbanization processes in Mediterranean regions by reconsidering (and possibly recomposing) the divide between urban morphology and economic functions (Faludi, 2006). Policies containing sprawl will benefit from multi-disciplinary and multi-scale approaches developing 'holistic', regional-wide visions (Giannakourou, 2005). A truly 'city 
region' planning perspective is required to manage the inherent complexity of contemporary cities.

\section{References}

Alberti, M. 2005. The effects of urban patterns on ecosystem function. International Regional Science Review, 28(2), 168-192.

Allegretti, G., Cellamare, C. 2008. The ambiguous renaissance of Rome. In: L. Porter and K. Shaw (eds.). Whose Urban Renaissance? An international comparison of urban regeneration strategies, pp. 129-138. New York: Routledge.

Allen, J., Barlow, J., Leal, J., Maloutas, T., Padovani, L. 2004. Housing in southern Europe. London: Blackwell.

Alphan, H. 2003. Land use change and urbanisation of Adana, Turkey. Land Degradation and Development, 14, 575-586.

Altshuler, A.A., Gomez-Ibanez, J.A. with A.M. Howitt. 1993. Regulation for Revenue: The Political Economy of Land Use Exactions. Cambridge, MA: Lincoln Institute of Land Policy and Washington, DC: The Brookings Institution.

Andersson, E. 2006. Urban landscapes and sustainable cities. Ecology and Society, 11(1), 34. Angel, S., Parent, J., Civco, D.L., Blei, A., Potere, D. 2011. The dimensions of global urban expansion: Estimates and projections for all countries, 2000 - 2050. Progress in Planning, 75, 53-107.

Anthony, J. 2004. Do State Growth Management Regulations Reduce Sprawl? Urban Affairs Review, 39(3), 376-397.

Arapoglou, V.P., Sayas, J. 2009. New facets of urban segregation in southern Europe. European Urban and Regional Studies, 16(4), 345-362.

Arribas-Bel, D., Nijkamp, P., Scholten, H. 2011. Multidimensional urban sprawl in Europe: A self-organizing map approach. Computers, Environment and Urban Systems, 35, 263275.

Balibrea, M.P. 2001. Urbanism, culture and the post-industrial city: challenging the 'Barcelona model'. Journal of Spanish Cultural Studies, 2(2), 187-210. 
Bayona-Carrasco, J., Gil-Alonso, F. 2012. Suburbanisation and international immigration: The case of the Barcelona Metropolitan Region (1998-2009). Tijdschrift voor Economische en Sociale Geographie, 103(3), 312-329.

Beriatos, E., Gospodini, A. 2004. Glocalising urban landscapes: Athens and the 2004 Olympics. Cities, 21(3), 197-202.

Bourne, L. 1996. Reinventing the suburbs: old myths and new realities. Progress in Planning, 4(3), 163-184.

Bruegmann, R. 2005. Sprawl: a compact history. Chicago: University of Chicago Press.

Burchfield, M., Overman, H.G., Puga, D., Turner, M.A. 2006. Causes of sprawl: a portrait from space. The Quarterly Journal of Economics, 121(2), 587-633.

Camagni, R., Gibelli, M.C., Rigamonti, P. 2002. Urban mobility and urban form: the social and environmental costs of different patterns of urban expansion. Ecological Economics, 40, 199-216.

Catalán, B., Saurí, D., Serra, P. 2008. Urban sprawl in the Mediterranean? Patterns of growth and change in the Barcelona Metropolitan Region 1993-2000. Landscape and Urban Planning, 85(3), 174-184.

Chorianopoulos, I., Tsilimigkas, G., Koukoulas, S., Balatsos, T. 2014. The shift to competitiveness and a new phase of sprawl in the Mediterranean city: Enterprises guiding growth in Messoghia-Athens. Cities, 39, 133-143.

Chorianopoulos, I., Pagonis, T., Koukoulas, S., Drymoniti, S. 2010. Planning, competitiveness and sprawl in the Mediterranean city: The case of Athens. Cities, 27, 249259.

Coccossis, H., Economou, D., Petrakos, G. 2005. The ESDP relevance to a distant partner: Greece. European Planning Studies, 13(2), 253-264.

Cohen, B. 2006. Urbanization in Developing Countries: Current Trends, Future Projections, and Key Challenges for Sustainability. Technology and Society, 28, 63-80.

Costa, F. 1991. Urban planning in Rome from 1870 to the first world war. Geojournal, 24, 269-276.

Couch, C., Karecha, J., Nuissl, H., Rink, D. 2005. Decline and sprawl: an evolving type of urban development - observed in Liverpool and Leipzig. European Planning Studies, 13(1), 117-136. 
Couch, C., Petschel-held, G., Leontidou, L. 2007. Urban Sprawl in Europe: Landscapes, Land-use Change and Policy. Blackwell: London.

Dahlman, C. 2006. Detour to Europe: Enlargement, Southeast Europe, and the EU's External Dynamic. Eurasian Geography and Economics, 47(6), 683-697.

De Muro, P., Monni, S., Tridico, P. 2011. Knowledge-Based Economy and Social Exclusion: Shadow and Light in the Roman Socio-Economic Model. International Journal of Urban and Regional Research, 35(6), 1212-1238.

Delladetsima, P. 2006. The emerging property development pattern in Greece and its impact on spatial development. European Urban and Regional Studies, 13(3), 245-278.

Dujardin, C., Selod, H., Thomas, I. 2008. Residential Segregation and Unemployment: The Case of Brussels. Urban Studies, 45(1), 89-113.

Dura-Guimera, A. 2003. Population deconcentration and social restructuring in Barcelona, a European Mediterranean city. Cities, 20, 387-394.

European Environment Agency 2006. Urban sprawl in Europe - The ignored challenge. Copenhagen: EEA Report no. 10.

Evans, G. 2003. Hard-branding the cultural city. From Prado to Prada. International Journal of Urban and Regional Research, 27(2), 417-440.

Faludi, A.K.F. 2006. From European spatial development to territorial cohesion policy. Regional Studies, 40(6), 667-678.

Galster, G., Hanson, R., Ratcliffe, M.R., Wolman, H., Coleman, S., Freihage, J. 2001. Wrestling sprawl to the ground: defining and measuring an elusive concept. Housing Policy Debate, 12(4), 681-717.

Garcia, D., Riera, P. 2003. Expansion versus density in Barcelona: a valuation exercise. Urban Studies, 40(10), 1925-1936.

Garcia-Palomares, J.C. 2010. Urban sprawl and travel to work: the case of the metropolitan area of Madrid. Journal of Transport Geography, 18, 197-213.

Giaccaria, P., Minca, C. 2010. The Mediterranean alternative. Progress in Human Geography, 35(3), 345-365.

Giannakourou, G. 2005. Transforming spatial planning policy in Mediterranean countries: Europeanization and domestic change. European Planning Studies, 13(2), 319-331. 
Gordon, P., Cox, W. 2012. Cities in Western Europe and the United States: do policy differences matters? Annals of Regional Science, 48(2), 565-594.

Gospodini, A. 2009. Post-industrial trajectories of Mediterranean European cities: the case of post-Olympics Athens. Urban Studies, 46, 1157-1186.

Haase, A., Kabisch, S., Steinführer, A., Bouzarovski, S., Hall, R., Ogden, P. 2010. Emergent spaces of reurbanisation: exploring the demographic dimension of inner-city residential change in a European setting. Population, Space and Place, 16(5), 443-463.

Haase, D., Tötzer, T. 2012. Urban-rural linkages. Analysing, modelling and understanding drivers, pressures and impacts of land use changes along the rural-to-urban gradient, Environment and Planning B, 39, 194-197.

Hatz, G. 2009. Features and Dynamics of Socio-spatial Differentiation in Vienna and the Vienna Metropolitan Region. Tijdschrift voor Economische en Sociale Geographie, 100(4), 485-501.

Helbich, M. 2012. Beyond Postsuburbia? Multifunctional Service Agglomeration in Vienna's Urban Fringe. Tijdschrift voor Economische en Sociale Geographie, 103(1), 39-52. Irwin, E.G., Bockstael N.E. (2004). Land use externalities, open space preservation, and urban sprawl. Regional Science and Urban Economics, 34(6), 705-725.

Jaeger, J. A., Bertiller, R., Schwick, C., Kienast, F. 2010. Suitability criteria for measures of urban sprawl. Ecological Indicators, 10(2), 397-406

Kabisch, N., Haase, D. 2011. Diversifying European agglomerations: evidence of urban population trends for the 21st century, Population, Space and Place, 17(3), 236-253.

Kahn, M.E. 2000. The environmental impact of suburbanization, Journal of Policy Analysis and Management, 19(4), 569-586.

Kasanko, M., Barredo, J.I., Lavalle, C., McCormick, N., Demicheli, L., Sagris, V., Brezger, A. 2006. Are European cities becoming dispersed? A comparative analysis of 15 European urban areas. Landscape Urban Planning, 77, 111-130.

Kloosterman, R.C., Musterd, S. 2001. The polycentric urban region: towards a research agenda. Urban Studies, 38(4), 623-633.

Kourliouros, E. 1997. Planning industrial location in Greater Athens: the interaction between deindustrialization and anti-industrialism during the 1980s. European Planning Studies, 5(4), 435-460. 
Kroll, F., Kabisch, N. 2012. The Relation of Diverging Urban Growth Processes and Demographic Change along an Urban-Rural Gradient, Population, Space and Place, 18(3), $260-276$.

Krumholz, N. 1992. Roman impressions: contemporary city planning and housing in Rome. Landscape and Urban Planning, 22(2-4), 107-114.

Laidley, T. 2015. Measuring Sprawl: A New Index, Recent Trends, and Future Research. Urban Affairs Review, doi:10.1177/1078087414568812.

Lang, R., Sanchez, T., Oner, A. 2009. Beyond edge city: Office geography in the new metropolis. Urban Geography, 30, 726-755.

Lemanski, C. 2007. Global Cities in the South: Deepening social and spatial polarisation in Cape Town. Cities, 24(6), 448-461.

Leontidou, L. 1990. The Mediterranean city in transition. Cambridge: Cambridge University Press.

Leontidou, L. 1996. Alternatives to modernism in (Southern) urban theory: Exploring inbetween spaces. International Journal of Urban and Regional Research, 20(2), 180-197.

Leontidou, L., Afouxenidis, A., Kourliouros, E., Marmaras, E. 2007. Infrastructure-related urban sprawl: mega-events and hybrid peri-urban landscapes in southern Europe. In: C. Couch, G. Petschel-Held, L. Leontidou (eds.). Urban sprawl in Europe: landscapes, landuse change and policy, pp. 71-101. Oxford: Blackwell.

Longhi, C., Musolesi, A. 2007. European cities in the process of economic integration: towards structural convergence. Annals of Regional Science, 41, 333-351.

Lopez, R., Hynes, H.P. 2003. Sprawl In The 1990s: Measurement, Distribution, and Trends. Urban Affairs Review, 38(3), 325-355.

Magliocca, N., McConnell, V., Walls, M. 2015. Exploring sprawl: results from an economic agent-based model of land and housing markets. Ecological Economics, 113, 114-125.

Maloutas, T. 2007. Segregation, social polarization and immigration in Athens during the 1990s: theoretical expectations and contextual difference. International Journal of Urban and Regional Research, 31(4), 733-758.

Melih Pinarcioğlu, M., Işik, O. 2009. Segregation in Istanbul: Patterns and Processes. Tijdschrift voor Economische en Sociale Geographie, 100(4), 469-484.

Muñoz, F. 2003. Lock living: Urban sprawl in Mediterranean cities. Cities, 20, 381-385. 
Nuissl, H., Rink, D. 2005. The 'production' of urban sprawl in eastern Germany as a phenomenon of post-socialist transformation. Cities, 22(2), 123-134.

Oueslati, W., Alvanides, S., Garrod, G. 2015. Determinants of urban sprawl in European cities. Urban Studies, 52(9), 1594-1614.

Pacione, M. 2005. Urban Geography: A Global Perspective. London: Routledge.

Paul, V., Tonts, M. 2005. Containing urban sprawl: trends in land-use and spatial planning in the Metropolitan Region of Barcelona. Journal of Environmental Planning and Management, 48(1), 7-35.

Phelps, N., Parsons, N., Ballas, D., Dowling, A. 2006. Post-suburban Europe. Planning and Politics at the Margins of Europe's Capital Cities. New York: Palgrave Macmillan.

Razin, E., Rosentraub, M. 2000. Are Fragmentation and Sprawl Interlinked?: North American Evidence. Urban Affairs Review, 35(6), 821-836.

Richardson, H.W., Chang-Hee, C.B. 2004. Urban sprawl in Western Europe and the United States. London: Ashgate.

Rivolin, U.J., Faludi, A.K.F. 2005. The hidden face of European spatial planning, European Planning Studies, 13(2), 195-215.

Rokach, L., Maimon, O. 2008. Data mining with decision trees: theory and applications. New York: World Scientific Publications.

Salvati, L. 2014. Towards a polycentric region? The socio-economic trajectory of Rome, an 'eternally Mediterranean' city. Tijdschrift voor Economische en Sociale Geografie, 105(3), 268-284.

Salvati, L., Carlucci, M. 2015a. Patterns of Sprawl: The Socioeconomic and Territorial Profile of Dispersed Urban Areas in Italy. Regional Studies, doi: 10.1080/00343404.2015.1009435.

Salvati, L., Carlucci, M. 2015b. In-Between Stability and Subtle Changes: Urban Growth, Population Structure, and the City Life Cycle in Rome. Population, Space and Place, doi: 10.1002/psp.1877.

Salvati, L., Gargiulo Morelli, V. 2014. Unveiling Urban Sprawl in the Mediterranean Region: Towards a Latent Urban Transformation? International Journal of Urban and Regional Research, 38(6), 1935-1953. 
Salvati, L., Sabbi, A. 2011. Exploring long-term land cover changes in an urban region of southern Europe. International Journal of Sustainable Development and World Ecology, 18(4), 273-282.

Salvati, L., Gargiulo, V., Rontos, K., Sabbi, A. 2013. Concentration or sprawl? Exploring demographic patterns in growing and declining Mediterranean urban regions. Urban Geography, 34(3), 376-394.

Sarzynski, A., Galster, G., Stack, L. 2014. Typologies of sprawl: investigating United States metropolitan land use patterns. Urban Geography, 35(1), 48-70

Schneider, A., Woodcock, C.E. 2008. Compact, dispersed, fragmented, extensive? A comparison of urban growth in twenty-five global cities using remotely sensed data, pattern metrics and census information. Urban Studies, 45, 659-692.

Schwarz, N., Haase, D., Seppelt, R. 2010. Omnipresent sprawl? A review of urban simulation models with respect to urban shrinkage. Environment and Planning B, 37, 265283.

Terzi, F., Bolen, F. 2009. Urban sprawl measurement of Istanbul. European Planning Studies, 17, 1559-1570.

Tsai, Y. 2005. Quantifying urban form: compactness versus sprawl. Urban Studies, 42(1), $141-161$.

Turner, M.A. 2005. Landscape preferences and patterns of residential development. Journal of Urban Economics, 57(1), 19-54.

Turok, I., Mykhnenko, V. 2007. The trajectories of European cities, 1960-2005. Cities, 24, $165-182$.

Non citati nel testo

Coisnon, T., Oueslati, W., Salanié, J. 2014. Urban sprawl occurrence under spatially varying agricultural amenities. Regional Science and Urban Economics, 44, 38-49.

Muñiz, I., Galindo, A., Angel Garcia, M. 2003. Cubic spline population density functions and satellite city delimitation: the case of Barcelona. Urban Studies, 40, 1303-1321.

Razin, E., Rosentraub, M. 2000. Are Fragmentation and Sprawl Interlinked?: North American Evidence. Urban Affairs Review, 35(6), 821-836. 
